Collection: Cost Action E29 Meeting 2008 - Istanbul (Turkey)

Future Monitoring and Research Needs for Forest Ecosystems

Guest Editor: Marcus Schaub (WSL, Birmensdorf, CH)

\section{Effective monitoring as a basis for adaptive management: a case history of mountain pine beetle in Greater Yellowstone Ecosystem whitebark pine}

\author{
Logan JA ${ }^{(1)}$, Macfarlane WW ${ }^{(2)}$, Willcox L ${ }^{(3)}$ \\ With reference to massive outbreaks of a variety of bark beetles occurring \\ across the forests of western North America, it is stressed that an accurate as- \\ sessment of the extent of the problem is the first step toward formulating ef- \\ fective adaptive management strategies. This assessment will only be possible \\ through a coordinated effort that combines all available technologies, that is \\ an approach that builds on satellite image analysis, aerial survey from fixed- \\ wing aircraft, and on the ground observation and measurement.
}

Keywords: Mountain pine beetle, Whitebark pine, Greater Yellowstone Ecosystem, Global warming, Disturbance ecology

\section{Introduction}

Massive outbreaks of a variety of bark beetles have recently, or are presently occurring across the forests of western North America. These outbreaks include the extensive die-off of piñon pine in the south west, devastating outbreaks of spruce beetle in Alaska, and unprecedented mountain pine beetle outbreaks in the U.S. and Canadian Rocky Mountains. Since all of these outbreaks involve native species, a basic question becomes differentiating between: those outbreaks that are within the range of historic variability; those that are outside the historic range of natural variability, but within the limits of ecosystem resiliency; and those that are truly a threat to continued ecosystem survival. In particular, two current outbreaks involving the mountain pine beetle most ap-

(1) P.O. Box 482, Emigrant, MT 59027 USA; (2) GeoGraphics Inc., 90 W Center St., Logan, UT 84321, USA; (3) Natural Resources Defense Council, Box 70, Livingston, MT 59047, USA

@ Jesse A. Logan (logan.jesse@gmail.com)

Received: Mar 13, 2008 - Accepted: Dec 09, 2008

Citation: Logan JA, Macfarlane WW, Willcox L, 2009. Effective monitoring as a basis for adaptive management: a case history of mountain pine beetle in Greater Yellowstone Ecosystem whitebark pine. iForest 2: 19-22 [online: 2009-01-21] URL:

http://www.sisef.it/iforest/show.php? id $=477$ pear to fall into the last category. These are the invasive range expansion into the boreal forest, and the eruption of sustained outbreak populations in high elevation, whitebark pine forests.

\section{Mountain pine beetle in lodgepole pine forests}

During the mid 1990's, when anthropogenic global warming was becoming an accepted fact by the mainstream scientific community, computer simulations indicated the potential for northern expansion of mountain pine beetle populations into previously unoccupied habitat, including the area of overlap between lodgepole and jack pine (Logan \& Powell 2001). It was further noted that if this occurred, overlapping pine habitat connected the entire North American continent from British Columbia to Texas. Subsequent events have corroborated these predictions (Powell \& Logan 2007). The previously impenetrable barrier of the Canadian Rockies was breached in 2003, and invading populations are now widespread in Alberta and the largest recorded MPB outbreak ever continues to expand (currently involving 13 million ha - Carroll 2006); and the hypothesized colonization of jack pine has occurred in the zone of overlap between jack and lodgepole pine (A. Carroll, personal communication). The last apparent barrier to continent-wide invasion is the long, dark, cold winter of the interior boreal forest. New quantitative tools will help anticipate the degree of climate warming required to overcome this barrier
(Régnière \& Bentz 2007). The Canadian government has committed significant resources to address both the ecological and social issues resulting from this epic event.

\section{Mountain pine beetle in whitebark pine forests}

The second unparalleled mountain pine outbreak is occurring across the range of whitebark pine, a foundation species for high-elevation forests of the northern U.S. Rocky Mountains (Fig. 1). The ecological amenities provided by whitebark pine are far-reaching, ranging from maintaining healthy watersheds to providing critical habitat for elk, bears, birds, squirrels, and other wildlife (Powell \& Logan 2007, Logan \& Powell 2009). Although mountain pine beetles are historically resident in whitebark pine, the ecological association was vastly different from that with lower-elevation lodgepole pine. Instead of being an irruptive species that co-evolved with the host, submarginal populations existed as a saprophyte in downed or weakened trees. Although outbreaks in whitebark pine have occurred during unusually warm periods, these have been of limited extent and duration. The climatic conditions in these high-elevation habitats were too severe for sustained outbreaks. However, increasing global temperatures has resulted in outbreak populations expanding into these previously inhospitable habitats. The result is an alarming intensification of widespread activity in vulnerable whitebark pine forests that began shortly after the turn of century (2002 or 2003). Nothing comparable to what is occurring today has been observed in recorded history or exists in the disturbance legacy of this long-lived species (Logan 2006).

\section{Whitebark pine in the Greater Yellowstone Ecosystem}

Nowhere is whitebark pine mortality more keenly felt than in the Greater Yellowstone Ecosystem (GYE), a geographically large (approximately 9,000,000 ha) and administratively complex (a mix of private ownership and lands managed by the National Park Service, the U.S. Forest Service, and the U.S. Fish and Wildlife Service) area that encompasses 16 major mountain ranges. The potential loss of whitebark pine in this sensitive ecosystem (Yellowstone National Park is the world's first national park and a United Nations World Heritage Site) holds severe consequences for a number of sensitive species including the grizzly bear. By raiding red squirrel middens that contain vast quantities of whitebark pine cones, grizzlies efficiently obtain a source of high-quality food from the large, nutritious whitebark pine seeds. This food resource becomes 


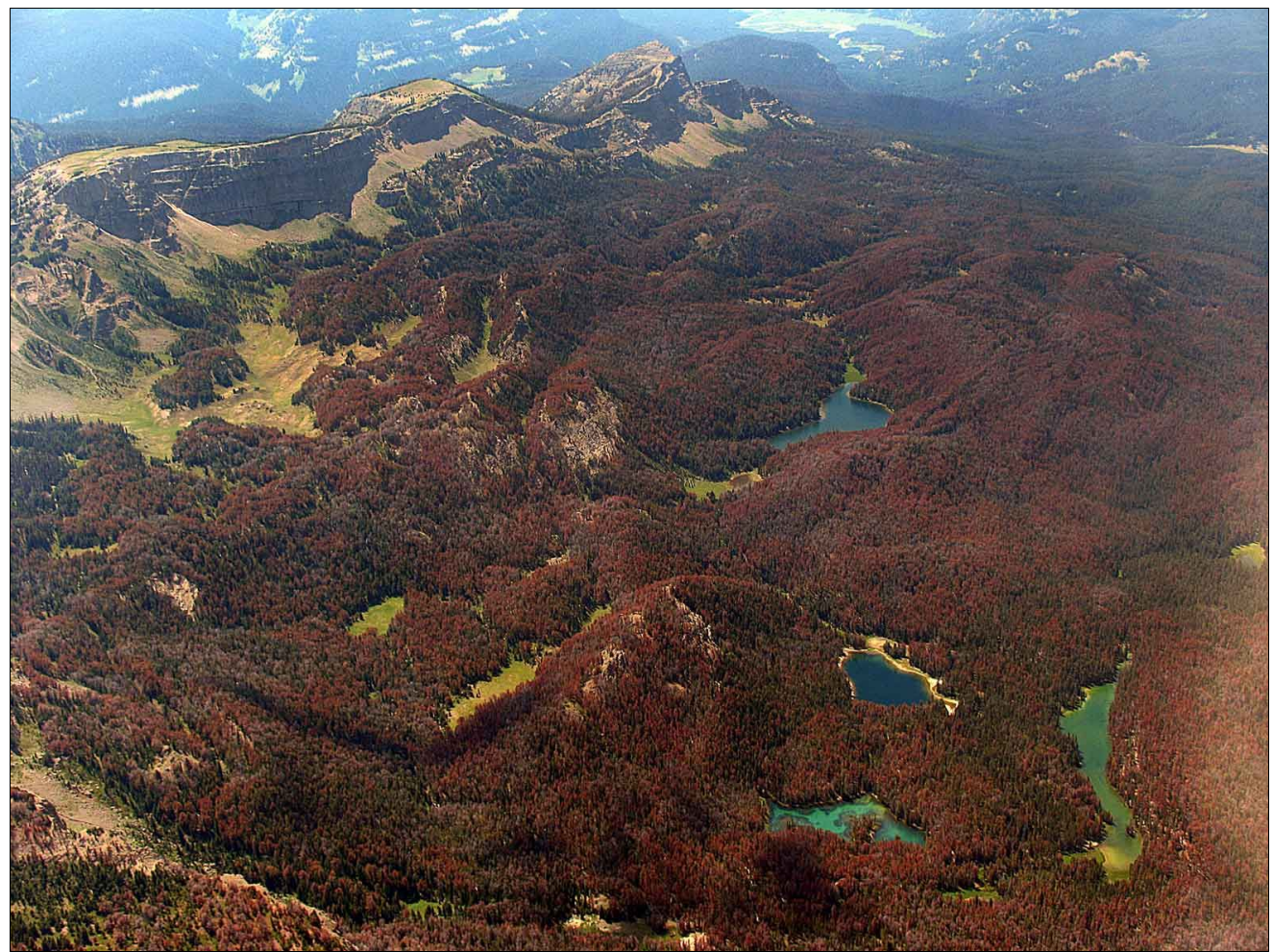

Fig. 1 - Mountain pine beetle mortality in whitebark pine. An example of the scale and intensity of mountain pine beetle mortality in whitebark pine of the Greater Yellowstone Ecosystem. This aerial photograph was taken by Jane Pargiter during the summer of 2007. The red trees were killed by mountain pine beetle during summer of 2006 , the gray trees were killed the previous summer. The few remaining green trees are probably currently infested, and will turn red the summer of 2008 .

available to the grizzly at a critical time - in the fall, just prior to entering hibernation. If female grizzlies enter hibernation when whitebark pine seed crops are poor, they produce fewer cubs. In addition, human-caused mortality rates greatly increase if whitebark pine crops fail, as grizzlies are driven to forage in lower-elevation areas where human conflicts become increasingly likely (Mattson et al. 1992, Gunther et al. 1997, Mattson 2000, Pease \& Mattson 1999).

Although catastrophic loss of whitebark pine in the GYE has already occurred, no one really knows its full extent. Regrettably, critical policy decisions are being made based on this inadequate information. The U.S. Fish and Wildlife's 2007 document supporting delisting the grizzly bear $(72 \mathrm{Fed}$ Reg. 14,866) stated that, “... (only) 16 percent of the total area of whitebark pine found in the GYA ... has experienced some level of mortality due to mountain pine beetles." It is clear that, even from the incomplete ADS data that is available, the figure is much higher (see Tab. 1). Clearly, there is a pressing need to first know the extent of the problem before rational management decisions can be made. The objective of the remainder of this contribution is to briefly describe ongoing development of a monitoring protocol designed to measure the full extent of mountain pine beetle caused mortality in whitebark pine in the GYE.

\section{Monitoring whitebark pine mortality}

Effective monitoring of whitebark pine loss presents unique difficulties since the high mountains occupied by this species are the among most rugged, inhospitable and remote habitats on the continent. Recognizing both the pressing need for, and the unique difficulties in obtaining, accurate monitoring data; a coalition of concerned citizens and non-governmental organizations has began formulating an approach that builds on satellite image analysis, aerial survey from fixedwing aircraft, and on-the-ground observation and measurement. Each will be briefly discussed.

\section{Satellite image analysis}

Satellite imagery directly addresses the issue of difficult terrain and remoteness. However, detecting the level of mortality has proven to be more difficult than originally anticipated. A recent description of both the difficulties and advances that have been made can be found in Hicke \& Logan (2009). Satellite image analysis is capable of providing a reliable estimate of previous year (red tree) mortality, but it seems unlikely that mortality will be measurable after the needles drop, leaving the gray stems. Additionally, satellite imagery of sufficient resolution is expensive, but not prohibitively so considering the ecological value of the resource.

\section{Aerial detection by human observer}

The principle measure of bark beetle activity is the USDA Forest Service's Aerial Detection Survey (ADS) that annually measures current season forest insect mortality. Due to the broad mandate of ADS to measure all insect mortality on public lands, ADS does not routinely include designated Wilderness Areas and National Parks; and Wilderness Areas and National Parks comprise nearly $1 / 3$ of the GYE. The distribution of whitebark pine is even more skewed, with almost $2 / 3$ of GYE whitebark pine in either Wilderness or National Parks. ADS has also prioritized economically important timber species like lodgepole pine, and as a result, whitebark pine has been under-surveyed. Recognizing these limitations to ADS, the Natural Resource Defence Council (NRDC) funded a pilot program during summer 2008 to evaluate feasibility of an aerial survey approach specifically designed to quantify mountain

Tab. 1 - Aerial detection survey for the Greater Yellowstone Ecosystem, 1999-2007. Although all of the Ecosystem was not surveyed every year, the level of mortality is a clear indication of both trend and magnitude of the ongoing outbreak.

\begin{tabular}{ccc}
\hline $\begin{array}{c}\text { Survey } \\
\text { Year }\end{array}$ & $\begin{array}{c}\text { Number of } \\
\text { Dead WBP }\end{array}$ & $\begin{array}{c}\text { Infested } \\
\text { Acres }\end{array}$ \\
\hline 1999 & 380 & 535 \\
2000 & 4166 & 2636 \\
2001 & 64273 & 28322 \\
2002 & 121278 & 49689 \\
2003 & 288603 & 75984 \\
2004 & 377920 & 136388 \\
2005 & 823646 & 135597 \\
2006 & 285490 & 147476 \\
2007 & 637588 & 171572 \\
\hline
\end{tabular}


Fig. 2 - Screen capture of GoOGLE EARTH $^{\circ} \cdot \mathrm{kml}$ file that contains NRDC Aerial survey results. Information retrievable from the GooGLE $^{\mathcal{O}}$ screen are, flight lines, location for point of photograph $(\mathrm{x}, \mathrm{y}, \mathrm{z})$, target center of photograph on the landscape, mortality category level, and the interpolated surface of mortality category.
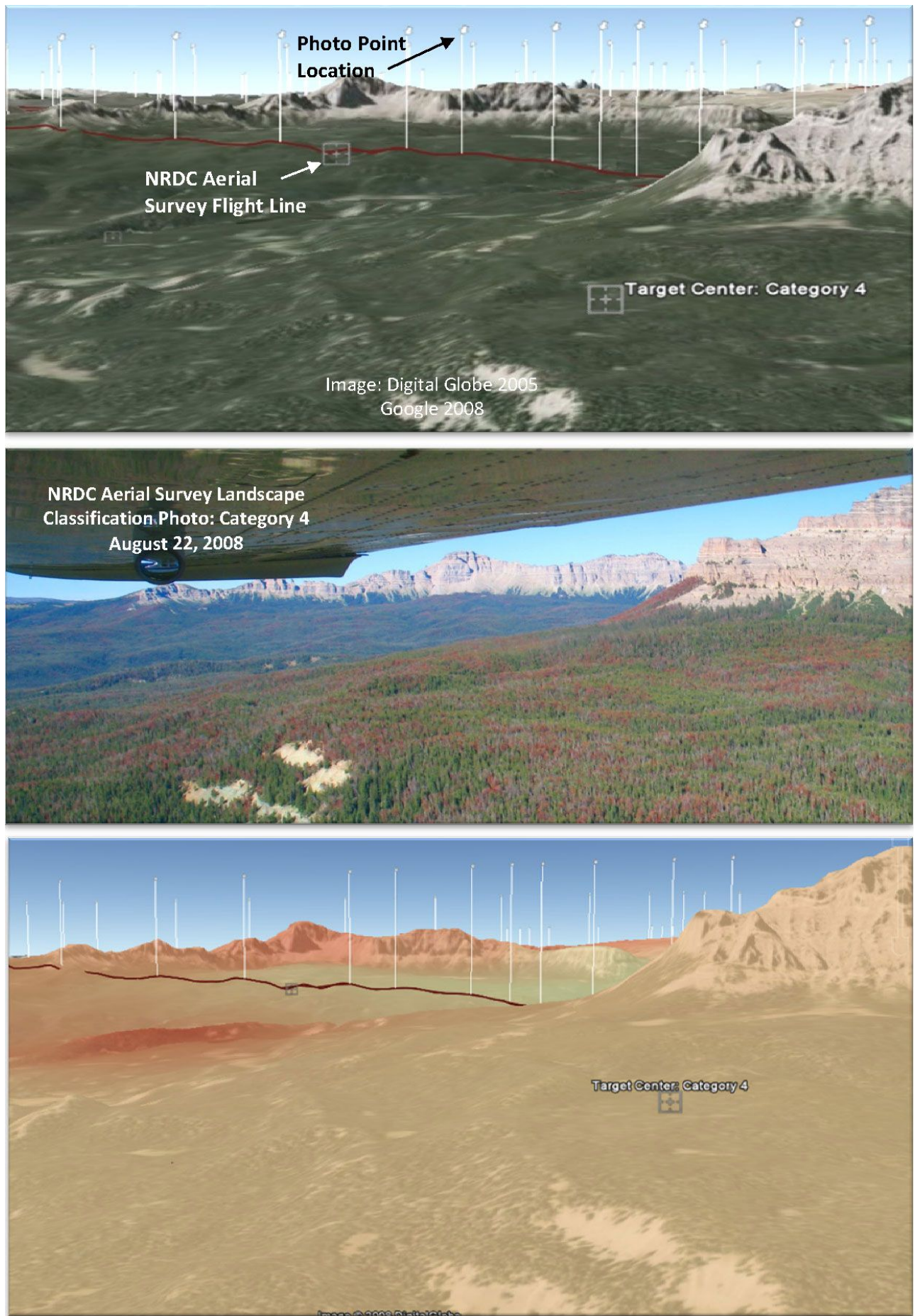

pine beetle mortality in GYE whitebark pine. The technique used in this study was landscape level classification of MPB impact into six categories, ranging from zero (no mortality outside of background levels) to five (the residual forest remaining after an outbreak runs its course). The survey results were photo-documented and georeferenced using Google EARTH $^{\mathcal{O}}$, and then used to generate a continuous impact map (Fig. 2). By focusing exclusively on whitebark pine distribution, and implementing a landscape classification based on the cumulative impact, this approach provided a cost-effective means to measure the integrated impact of mortality that has occurred beginning in the early 2000s. The results are encouraging, and funding is being sought to support flying the entire GYE in summer 2009.

\section{On the ground evaluation}

Some important ecological observations cannot be made from either satellite imagery or from aircraft flying over $200 \mathrm{mph}$ at 16
$000 \mathrm{ft}$. elevation. Recognizing this ecological limitation, a group of citizens most impacted by the loss of whitebark pine was organized to document the level of whitebark pine mortality across the entire ecosystem. Documentation procedures and protocols have evolved and been formalized through funding provided by NRDC. The observation by citizen scientists will be used to verify aerial detection results and to evaluate critical factors, like recruitment of seedlings and saplings, that cannot be measured through 
remote sensing. Citizen scientist observations will also augment results of more formal stand survey information provided by land management agencies.

\section{Conclusion}

Although important management decisions like the Grizzly Bear delisting rule illustrate the need for effective monitoring, all downstream ecological amenities provided by whitebark pine are impacted by loss of this foundation species. Accurately accessing the extent of the problem is the first step toward formulating effective adaptive management strategies, and this assessment will only be possible through a coordinated effort that combines all available technologies.

\section{Acknowledgments}

We thank Natural Resource Defense Council for generous support for much of this work, and ESRI for supplying JAL a conservation copy of ARcMAP and associated GIS software.

\section{References}

Carroll A (2006). Changing the climate, changing the rules: global warming and insect disturbance in western North American forests. PowerPoint presentation: MTCLIM 2006 Conference, Mt. Hood Oregon, September 2006. [online] URL: http://www.fs.fed.us/psw/cirmount/meetings/mtc lim/2006/talks/pdf/carroll_talk_mtclim2006.pdf Gunther KA, Bruscino MT, Cain S, Frey K, Knight RR (1997). Grizzly bear-human conflicts, confrontations, and management actions in the Yellowstone ecosystem, 1996. Interagency Grizzly Bear Committee, Yellowstone Ecosystem Subcommittee report. U.S. Department of the Interior, National Park Service, pp. 43 (unpublished report).

Hicke JA, Logan JA (2009). Mapping whitebark pine mortality caused by a mountain pine beetle outbreak with high spatial resolution satellite imagery. International Journal of Remote Sensing (in press).

Logan JA (2006). Yellowstone case study of wildlife effects: global warming, whitebark pine, and grizzly bears In Yellowstone. In: "Losing ground: western National Parks endangered by climate disruption" (Saunders S, Easley T eds). NRDC New York, USA. [online] URL: http://www.rockymountainclimate.org/website \%20pictures/Losing\%20Ground.pdf

Logan JA, Powell JA (2001). Ghost forests, global warming, and the mountain pine beetle. Americ- an Entomologist 47: 160-173.

Logan JA, Powell JA (2009). Ecological consequences of climate change: altered insect disturbance regimes. In: "Climate change in western north america: evidence and environmental effects" (Wagner FH ed). University of Utah Press, Utah, USA (in press).

Mattson DJ (2000). Causes and consequences of dietary differences among Yellowstone grizzly bears (Ursus arctos). Ph. D. Dissertation, University of Idaho, Moscow, USA.

Mattson DJ, Blanchard BM, Knight RR (1992). Yellowstone grizzly bear mortality, human habituation, and whitebark pine seed crops. Journal of Wildlife Management 56: 432-442. - doi: 10.2307/3808855

Pease CM, Mattson DJ (1999). Demography of the Yellowstone Grizzly bears. Ecology 80: $957-$ 975. [online] URL: http://fresc.usgs.gov/products/papers/590_Pease.pdf

Powell JA, Logan JA (2007). Insect seasonality: circle map analysis of temperature-driven life cycles. Theoretical Population Biology 67: 161179. - doi: 10.1016/j.tpb.2004.10.001

Régnière J, Bentz BJ (2007). Modeling cold tolerance in the mountain pine beetle, Dendroctonous ponderosae. Journal of Insect Physiology 53: 559-572. - doi: 10.1016/j.jinsphys.2007.02.007 